\title{
Uncertainty Expressions in Accounting: Critical Issues and Recommendations
}

\author{
Yuqian Zhang ${ }^{1}$, Anura De Zoysa ${ }^{2}$ and Corinne Cortese ${ }^{3}$
}

\begin{abstract}
Uncertainty expressions are used in accounting contexts to describe business information. Due to the widespread use of uncertainty expressions, accounting scholars have critically assessed their potential impacts in financial reporting, as well as in the context of judgement and decision-making behaviour. In line with this topic, this paper outlines several fundamental issues related to uncertainty expressions and grounds these research paradigms and empirical findings in the context of the behavioural-psychology literature. In this study, we propose a solution to reduce potential impacts of uncertainty expressions in accounting. We advocate the Verbal-Numerical (V-N) Scale strategy for the communication of objective accounting information. We also recommend the V-N Disclosure strategy for the communication of subjective accounting information by associating a mathematical strategy. Practical limitations and implications for future accounting research on uncertainty expressions are also discussed.
\end{abstract}

JEL classification: M40.

Keywords: Uncertainty Expressions, Accounting Standards, V-N Scale, V-N Disclosure, Accounting Information

\footnotetext{
${ }^{1}$ Department of Finance, Accounting and Economics, University of Nottingham, Ningbo China. Corresponding Author: Yuqian Zhang, University of Nottingham Ningbo China, Faculty of Business, 199 Taikang East Road, Ningbo, 31500, China, Email: yuqian.zhang@notttingham.edu.cn

${ }^{2}$ School of Accounting, Economics and Finance, University of Wollongong, Australia

${ }^{3}$ School of Accounting, Economics and Finance, University of Wollongong, Australia
} 


\section{Introduction}

Scholars and practitioners often consider accounting as the language of business. Academically, accounting is considered as a special-purpose tool for communicating about financial state and performance (Bloomfield, 2008). Professionally, accounting is viewed as an international business language that plays an infrastructural role in business activities (Deloitte, 2017). Accounting standards are essential parts of the accounting language. Using the International Financial Reporting Standards (IFRS) as an example, up to 156 jurisdictions consider the IFRS as the global financial reporting language, and 144 of them require IFRS Standards for all or most domestic publicly accountable entities (IFRS Foundation, 2019).

IFRS are principle-based accounting standards that are designed for interpretation and professional judgement (Bradbury \& Schröder, 2012). Prior studies have stressed that IFRS lacks guidelines on how to use uncertainty expressions (Du \& Stevens, 2011; Huerta, Petrides, \& Braun, 2016; Salleh, Gardner, Sulong, \& McGowan, 2011). For example, when measuring the fair value of an asset, a reporting entity should assess the 'reasonably possible alternative assumption' (section 93) or 'expected cash flow' (section B13) of the accounting item. The terms reasonably possible and expected are uncertainty expressions, and the meaning of these terms are subject to professional interpretations and judgement (Chesley, 1986; Davidson \& Chrisman, 1994; Doupnik \& Richter, 2003). Due to their reliance on professional interpretation and judgement, uncertainty expressions often lack consistent meanings, and such inconsistencies will reduce the comparability between companies' financial statement (Simon, 2002). Accordingly, understanding the nature and impact of uncertainty expressions is vital for accounting research.

Uncertainty information can be communicated in two ways: as verbal uncertainty expressions (for example, highly likely), or as numerical uncertainty expressions (for example, a 70\% chance). Prior studies have concluded that people perceive and interpret verbal and numerical uncertainty expressions significantly differently across cultures, languages, and educational and professional backgrounds (see Chand, Cummings, \& Patel, 2012; Doupnik \& Riccio, 2006; Simon, 2002). Such deviations across meanings and interpretations could impair communication efficiency in accounting (Laswad \& Mak, 1997). Moreover, more concerns about the use of uncertainty expressions and their negative impact on judgement and decision-making have emerged (Chand et al., 2012; Piercey, 2009).

Although evidence that stresses the problems related to the use of uncertainty expressions in accounting has accumulated, accounting regulators and practitioners are yet to propose a solution. For instance, IFRS 5 provides little guidance on the meaning of uncertainty expressions, noting that "probable $=$ more likely than not" and "highly probable = significantly more likely than probable" (IFRS 5 . Appendix A). Accordingly, this leads to a critical question regarding the fundamental meanings of uncertainty expressions and how they can be used effectively to facilitate financial reporting and decision-making.

This paper systematically reviews theoretical and empirical findings related to uncertainty expressions from the behavioural-psychology literature. Based on the literature, this study summarises uncertainty information and its embedded expressions into two categories: objective information and subjective information. Following this, this paper proposes two separate strategies based on the characteristics of uncertainty information. The VerticalNumerical (V-N) Scale strategy is proposed to address the communication of objective information, and the V-N Disclosure strategy is proposed to solve the communication of subjective information. Both strategies are proposed based on empirical evidence and valid 
reasoning. Following these strategies, both preparers and users of accounting information can freely use and evaluate uncertainty expressions in financial reports with a reasonable assurance of the information's accuracy.

\section{Background}

\section{Uncertainty expression: a tale of two modes}

There are two modes of uncertainty expressions (Erev \& Cohen, 1990): numerical and verbal uncertainty expressions. Numerical probability expressions can be displayed as a percentage (e.g. $60 \%$ ), a frequency (e.g. 30/50, or 30 out of 50), or decimal (e.g. 0.6). Verbal probability expressions are words or phrases that people use intuitively to express the likelihood of an event (Lichtenstein \& Newman, 1967). They can be expressed as a single word, such as "likely", as a phrase that includes a modifier, such as "highly likely", or as a word with a prefix, such as "unlikely". Table 1 gives a summary of numerical and verbal uncertainty expressions.

Table 1 - Modes of uncertainty expressions

\begin{tabular}{|c|c|}
\hline Verbal uncertainty expressions & Numerical uncertainty expressions \\
\hline $\begin{array}{l}\text { - Single word } \\
\text { e.g., probable; likely; possible }\end{array}$ & $\begin{array}{l}\text { - } \quad \text { Percentage (can include range) } \\
\text { e.g., } 50.0 \% ; 35.2 \% \text { to } 89.8 \% \text {; }\end{array}$ \\
\hline $\begin{array}{l}\text { - } \quad \text { Modifier + word } \\
\text { e.g., very likely; highly probable; less likely }\end{array}$ & $\begin{array}{l}\text { - Frequency (can include range) } \\
\text { e.g., } 4 / 10 ; 3 / 13 \text { to } 8 / 13\end{array}$ \\
\hline 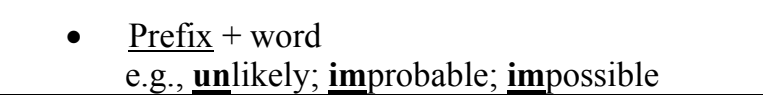 & $\begin{array}{l}\text { - Decimal (can include range) } \\
\text { e.g., } 0.25 ; 0.3 \text { to } 0.5\end{array}$ \\
\hline
\end{tabular}

Both modes of uncertainty expressions are used extensively. From public news reports to the official accounting standards, they are seamlessly integrated into daily conversations and form the basis of many people's conscious and subconscious judgements. For example, in responding to public concerns about the Australian economy, the Reserve Bank of Australian reported:

It is "highly unlikely" that Australia's economy entered a recession over the second half of last year, the Reserve Bank has concluded in its latest economic update (ABC News, 2017a).

Similarly, after several terrorist incidents occurred domestically and globally in 2017 , the Australian government ${ }^{4}$ announced that:

Australia's terror threat level remains at "probable" (ABC News, 2017b).

Occasionally both modes of uncertainty expression are used in the same message. For example, the statement below uses two types of numerical probabilities (range probability: 30-40\%; frequency: 1-in-2 chance) to correlate with one verbal probability (reasonably high).

\footnotetext{
${ }^{4}$ In fact, the Australian government only uses a five-level verbal scale to advise on the likelihood of a terrorist action in Australia: Not Expected, Possible, Probable, Expected and Certain (Australian National Security, 2017). The report provides no numerical definition or scales for these verbal expressions.
} 
.... [there is a] "reasonably high" chance [the] AAA rating will be lost before Christmas - Australia has almost a one-in-two chance of being downgraded next week... with a slowing economy and widening budget deficit, he sees a "reasonably high" 30 to 40 per cent chance of Australia being downgraded... (ABC News, 2016).

This mixed usage, as shown above, illustrates a critical issue when communicating using uncertainty expressions. The two numerical probabilities (one-in-two chance and 30 to 40 per cent) are statistically different. The verbal term "reasonably high" also does not necessarily correlate to either of these two numerical probabilities. On close examination, therefore, it appears that this message conveys information that lacks precision or is highly subjective.

\section{Uncertainty expressions: definitions and applications}

A specific solution for practical usage of uncertainty expressions requires an understanding of the context within which uncertainty expressions are used in accounting. In general, accounting scholars associate the use of uncertainty expression with the contexts of uncertainty (Chesley, 1986; Doupnik \& Richter, 2003), risk (Juanchich, Sirota, \& Butler, 2012), and ambiguity (Nelson \& Kinney Jr, 1997). The consideration of these terms as synonymous with notions of uncertainty may lead to research flaws, as it overlooks some of the unique characteristics of uncertainty expressions. For example, an uncertainty expression may either be the result of or contribute to ambiguity. However, an uncertainty expression need not necessarily be related to ambiguity at all. Accordingly, there is a need to clarify the terms 'uncertain', 'risk', and 'ambiguous'.

Table 2 - Definitions and applications of uncertain, risk, and ambiguity

\begin{tabular}{|c|c|c|c|c|}
\hline Context & $\begin{array}{l}\text { Definition } \\
\text { (Oxford English Dictionary) }\end{array}$ & $\begin{array}{l}\text { Subjective/ } \\
\text { Objective }\end{array}$ & Application & $\begin{array}{l}\text { Examples of } \\
\text { application } \\
\text { (Accounting) }\end{array}$ \\
\hline \multirow{2}{*}{ Uncertain } & & Objective & $\begin{array}{l}\text { Information } \\
\text { Quality }\end{array}$ & \multirow{2}{*}{$\begin{array}{l}\text { Chesley, 1986; } \\
\text { Doupnik and } \\
\text { Richter, } 2003\end{array}$} \\
\hline & $\begin{array}{l}\text { Not completely confident or } \\
\text { sure }\end{array}$ & Subjective & Confidence & \\
\hline \multirow{2}{*}{ Risk } & $\begin{array}{l}\text { Involving the possibility of } \\
\text { injury, loss, or other adverse or } \\
\text { unwelcome circumstance; }\end{array}$ & Objective & Outcome & \multirow{2}{*}{$\begin{array}{l}\text { Juanchich, et } \\
\text { al., } 2012\end{array}$} \\
\hline & $\begin{array}{l}\text { The error of observation or } \\
\text { result considered without regard } \\
\text { to sign; the probability of error }\end{array}$ & Objective & Error & \\
\hline \multirow[b]{2}{*}{ Ambiguous } & $\begin{array}{l}\text { Wavering of opinion; hesitation, } \\
\text { doubt, uncertainty as to one's } \\
\text { course }\end{array}$ & Subjective & Opinion & \multirow{2}{*}{$\begin{array}{l}\text { Nelson and } \\
\text { Kinney Jr, } 1997\end{array}$} \\
\hline & $\begin{array}{l}\text { The capability of being } \\
\text { understood in two or more } \\
\text { ways; double or dubious } \\
\text { signification }\end{array}$ & Subjective & Understandability & \\
\hline
\end{tabular}

Table 2 summarises the overall contexts and attributes of uncertainty expressions. As shown in Table 2, these terms are distinct from each other in both their definitions and subjective/objective nature (Oxford English Dictionary, 2002). In the field of psychology, scholars also applied these terms significantly different in their experiments. 
Discussions on their differences can be traced to as early as the 1920s, when Frank Knight ${ }^{5}$ asserted that uncertainty can be either measurable or unmeasurable. Measurable uncertainty is referred to as risk and can be represented by numerical probabilities (see reviews in: Ellsberg, 1961). Ellsberg, (1961) extended this statement to argue that some uncertainties are not risks because people do not necessarily behave according to precise numerical estimations. This view led to the famous Ellsberg Paradox: people's decisions can violate the postulate of subjective expected utility (Segal, 1987). In the same article, Ellsberg added another dimension of uncertainty, which he called ambiguity, that indicates the quality of information as determined by its amount, type and reliability.

\section{Uncertainty expressions: IFRS}

IFRS contains a significant amount of uncertainty expressions. A thorough review of IFRS reveals the use of more than 40 different verbal uncertainty expressions covering almost every aspect of financial reporting, such as judgement on accounting item recognition and disclosure (Appendix 1). Similarly, entities which have adopted the IFRS also use similar terms in their financial and annual reports, either those directly quoted from the IFRS or similar ones.

Due to IFRS's principles-based approach, using uncertainty expressions under IFRS does provide benefits for accounting communication: they facilitate professional judgement and allow adjustments between different jurisdictions (e.g., countries) with different economic and cultural scales (Weiss, 2008; Zeff, 2007). However, the use of uncertainty expressions also creates significant challenges in achieving consistent accounting judgement (Chand et al., 2012; Erb \& Pelger, 2015).

First, accounting-information preparers using accounting standards need to understand the meaning of the uncertainty expressions they choose to use, including how they represent uncertainty level, and if applicable, how they are interpreted numerically. Each reader may perceive verbal uncertainty expressions differently (see Brun \& Teigen, 1988; Juanchich et al., 2012), and prior studies have already demonstrated that language and personal attributes could significantly influence how they are interpreted (see Chand et al., 2012; Davidson \& Chrisman, 1994; Doupnik \& Richter, 2003; Huerta, Petrides, \& Braun, 2013).

Second, using verbal uncertainty expressions in accounting standards may have unintended consequences for information manipulation. Since people perceive verbal uncertainty expressions differently, and because the accounting standard regulators have not issued standardised numerical scales, accounting-information preparers may be able to take advantage of ambiguity in verbal expressions to disguise risks and adverse business outcomes (Kelton \& Montague, 2018; Piercey, 2009). Piercey, (2009, p. 331) describes information preparers as the 'word-smiths' of accounting information, manipulating verbal uncertainty expressions to encourage readers to reach the preparers' preferred conclusions.

Third, and perhaps most controversial, is that using verbal uncertainty expressions in accounting standards would impair the communication efficiency, thus lowing the quality of

\footnotetext{
${ }^{5}$ Wright, an economist from the University of Chicago, was best known as the author of the book Risk, Uncertainty and Profit. He was also the doctoral advisor of Nobel laureates George Stigler and James Buchanan.
} 
accounting judgement and decision (Laswad \& Mak, 1997; Simon, 2002). Simon, (2002) argued that many verbal uncertainty expressions lack consensus in interpretation, and thereby resulting in a low communication efficiency in financial reporting. Moreover, empirical findings from behavioural psychology stress that people display certain judgement biases towards verbal uncertainty expressions. One of these is the directionality effect: the fact that verbal expressions can communicate a double message (Budescu, Karelitz, \& Wallsten, 2003; Teigen \& Brun, 1999). For example, the expressions 'possible' and 'uncertain' are widely used in both IFRS and IAS pronouncements, but the directionality effect often leads people to judge that the term 'possible' means that an event may occur, and the term 'uncertain' means that the event may not occur. However, studies have shown that numerical interpretations of 'possible' and 'uncertain' are very similar at around $41 \%$ to $45 \%$ (Appendix 2).

\section{Uncertainty expressions: research paradigms}

Theoretically, people may use verbal and numerical uncertainty expressions interchangeably. Some researchers have suggested that numerical uncertainty expression serve as numerical translations of (Beyth-Marom, 1982) or give quantitative meaning to (Reagan, Mosteller, \& Youtz, 1989) verbal uncertainty expressions; similarly, verbal expressions represent a “qualitative expression” (Mosteller \& Youtz, 1990, p. 2) of numbers.

According to Hardman and Macchi, (2003), research on uncertainty expressions includes three major paradigms: translation, semantic and pragmatic. Most uncertainty expressions studies are based on the translation paradigm: finding the most effective method to translate verbal probabilities into numbers. A general method is to provide a percentage from 0 to 100 that corresponds to the verbal phrases, which Reagan et al., $(1989$, p. 433) refer to as the "word-to-number" conversion. Another method is to judge the degree of uncertainty over the $[0,1]$ scale or $p$-value in a specific context, which is referred to as the membership function (Wallsten, Fillenbaum, \& Cox, 1986).

Studies based on the translation paradigm began in the 1960s. For example, in a survey that Lichtenstein and Newman, (1967) conducted for a company, 41 verbal uncertainty expressions were interpreted using decimal terms. Similar studies have been conducted in forecasting (Beyth-Marom, 1982) and organisational behaviour (Brun \& Teigen, 1988).

Notably, a research approach based on the translation paradigm has been particularly popular in accounting (see Chand et al., 2012; Chesley, 1986; Davidson \& Chrisman, 1994; Doupnik \& Riccio, 2006; Doupnik \& Richter, 2003; Doupnik \& Richter, 2004; Hu, Chand, \& Evans, 2013; Laswad \& Mak, 1997). A typical context in accounting research is to investigate the cross-national and cross-lingual variances of word-to-number conversion. The example below is drawn from a study of the word-to-number conversion between German and American accountants in Doupnik and Richter's 2003 study (p.32):

\section{Example}

Please indicate the probability in percentage terms that best corresponds, in your opinion, to the following expression:

Reasonably likely $\%$

Another stream of uncertainty-expression research has followed a semantic paradigm; that is, it targets the inherent meaning of verbal expressions that may not be captured by numerical expressions. One typical example is the research on the directionality of uncertainty 
expressions (see Budescu et al., 2003; Teigen \& Brun, 1999). Directionality refers to the unique characteristics of verbal uncertainty expressions in directing people's probability judgement. For instance, when deciding options for a business strategy, "Strategy A's success is somewhat possible" directs one to anticipate a positive outcome, whereas "Strategy B's success is uncertain" directs one to anticipate an adverse outcome. As evident in prior literature (Appendix 2), possible and uncertain share similar numerical meanings but differ significantly in terms of directional meanings. As a result, research findings based on the semantic paradigm could be problematic when compared to those based on the translation paradigm. Because word-to-number conversion may be inconsistent with the direction of the verbal expression, they may not capture how people think and react to uncertainty expressions.

Furthermore, some studies focus on understanding the effect of uncertainty expressions in judgement and decision-making: the so-called pragmatic paradigm. This paradigm, which has been fruitful in experimental psychology, is primarily based on laboratory experiments. The standard research approach is to recruit university students as subjects and document their uncertainty judgements based on uncertainty expressions. For example, Budescu, Weinberg, and Wallsten, (1988) designed two experiments to assess students' decisions based on verbal and numerical uncertainty expressions. They used bidding and rating as the proxies for uncertainty judgements and found that judgements based on numerical uncertainty expressions were more consistent than those based on verbal expressions. The pragmatic research approach has also revealed variances in information-processing time between verbal and numerical expressions (Jaffe-Katz, Budescu, \& Wallsten, 1989). Subsequent studies, such as Gonzalez-Vallejo, Erev, and Wallsten, (1994), also found that uncertainty expressions influence decision quality.

\section{Uncertainty expressions: communication biases}

Using uncertainty expressions in risk communication may raise several concerns. For example, research has shown that people tend to receive uncertainty information numerically and express it verbally (Erev \& Cohen, 1990). This preference paradox between verbal and numerical uncertainty expressions is referred to as the Communication-Mode Preference (CMP). The CMP indicates that people who prepare uncertainty information prefer to use verbal uncertainty expressions because they allow a certain degree of flexibility and subjectivity.

In contrast, people who make decisions based on uncertainty information prefer to describe the uncertainty in numbers, as they are less subjective and less likely to induce judgement biases. For example, Wallsten, Budescu, Zwick, and Kemp, (1993) surveyed 442 university students, asking their preferences regarding verbal and numerical probability communications. The survey results showed that participants preferred to receive information numerically and to convey it verbally. $\mathrm{Xu}, \mathrm{Ye}$, and $\mathrm{Li},(2009)$ surveyed 370 native Chinese speakers about their preference for verbal and numerical uncertainty communication and found a similar pattern. Collectively, the CMP exposes a valid concern: how to ensure people can use both modes of expressions effectively in uncertainty communication.

Another type of bias associated with the use of uncertainty expressions is severity bias (Harris \& Corner, 2011): people often tend to overestimate the probability when the expected outcome is adverse and severe. Some of the empirical evidence that supports the existence of this bias is found in the uncertainty communication between doctors and patients. In 
Bonnefon and Villejoubert's (2006) study, subjects interpreted a doctor's information about 'possible deafness' into significantly higher numerical probabilities than the information about 'possible insomnia'. Such bias in interpretation corresponds with the semantic research paradigm mentioned earlier.

Based on empirical findings, the use of uncertainty expressions could lead to several constraints in risk communication, judgement and decision-making. Three points summarise the mechanism behind these constraints.

First, verbal and numerical uncertainty expressions are not necessarily interchangeable to describe levels of uncertainty. For example, the occurrence of an event is at a high uncertainty level (in other words, less certain) when its numerical probability is a 50-50 chance (also see: Beyth-Marom, 1982, pp. 266-267), and at a low uncertainty level (in other words, more certain), when its numerical probability is either extremely small (e.g. 5\%) or extremely large (e.g. 95\%).

Second, verbal uncertainty expressions differ to numerical uncertainty expressions in their degree of vagueness. Some extreme expressions such as 'absolutely impossible' or 'absolutely certain' have a much narrower range of possible meanings than moderate expressions such as 'uncertain' (Hamm, 1991).

Third, verbal uncertainty expressions are more subjective than numerical (Juanchich \& Sirota, 2013; Teigen \& Brun, 1999; Windschitl \& Wells, 1996); thus numerical uncertainty expressions can be perceived as less credible. For example, Piercey, (2009) observed that using verbal uncertainty expressions can induce motivational reasoning: verbal expressions are perceived as more biased and more justifiable than numerical uncertainty expressions. Such subjectivity can also be the result of the impact of context on verbal uncertainty expressions (see Teigen \& Brun, 2003), or changes in people's perception of words' meanings over time (see Karelitz \& Budescu, 2004).

\section{Solutions for Accounting}

Definitions and discussions found in the literature suggest that uncertainty expressions can be used in different contexts when providing objective or subjective information. The rationale for using uncertainty expressions to communicate objective information can be attributed to the lack of exact knowledge about a measurand's value, such as outcome, error and information quality. In contrast, the rationale for using uncertainty expressions to communicate subjective information is mainly due to personal interpretations of uncertainty, such as confidence, opinion, and understandability. Based on these differences, this study proposes two strategies for using uncertainty expressions in accounting: the Verbal Numerical (V-N) Scale strategy addresses objective uncertain accounting information and the V-N Disclosure strategy links to the subjective uncertain accounting information.

\section{Strategies of usage: V-N Scale and V-N Disclosure}

As discussed above, the specific application of uncertainty expressions in an accounting context relies on whether the accounting information is objective or subjective. This paper develops two separate strategies - objective and subjective - for reporting, communicating, and estimating uncertain accounting information using uncertainty expressions. 


\section{V-N Scale: Objective accounting information}

The V-N Scale represents the reporting and communicating of objective uncertain accounting information using a standardised word-to-number scale. A common approach to disclosing objective uncertainty information is to include the error factors or confidence intervals in the communication (e.g., Joint Committee for Guides in Metrology, 2010); for example:

\section{Best estimated value \pm Errors}

One advantage of such disclosure is that adding the error factors would not affect the mean value of the item, and thus would not affect the reporting figures in the financial statement. On the other hand, providing the error factors could both alert information users to any uncertainty issues and assist information preparers in monitoring the accuracy of the error factors.

When reporting objective uncertain information, information preparers should choose the least vague verbal probability expression; that is, the one that should yield the smallest variations in numerical interpretation. For example, a person knows that a standardised verbal probability of $80 \% \pm 10 \%$, has been assigned to the phrase 'very likely', and one of $80 \% \pm 5 \%$ has been assigned to 'highly probable'. Because the possibility for error is smaller for 'highly probable', the person can consider this to be the proper option. This example indicates that the use of standardised verbal expressions of uncertainty could help reduce the ambiguity or vagueness of the uncertainty information, a characteristic that could be of value in financial reporting.

The V-N Scale has been adopted in several professional estimation settings. This paper provides examples of the use of the V-N Scale in three domains: the Intergovernmental Panel on Climate Change (IPCC), behaviour psychology and intelligence analysis.

Guidelines for an uncertainty-expression scale has emerged from the research on climate change. Because the Intergovernmental Panel on Climate Change (IPCC) must report its activities to a global audience, its challenges include not only the standardisation of uncertainty expressions but their translation and interpretation between different languages. Notably, the IPCC's discussion of guidelines for uncertainty expressions has been informed by studies such as Risbey and Kandlikar, (2007), Budescu, Broomell, and Por, (2009), Harris and Corner, (2011), and Budescu, Por, and Broomell, (2012).

In the field of behavioural psychology, several attempts to develop word-to-number scales have been made in studies such as Beyth-Marom, (1982), Hamm, (1991), and Witteman and Renooij, (2003). Although they have a common purpose of standardising uncertainty expressions, the scales from these studies have different structures or properties. For example, Beyth-Marom's (1982) scale is displayed horizontally, with the percentage modes of numerical probabilities forming column headers; Hamm's (1991) scale arranges the pvalue mode of numerical probabilities vertically; and Witteman and Renooij, (2003) propose a short vertical scale for the percentage mode of numerical probabilities.

In the field of intelligence and national security research, researchers have also proposed standardised word-to-number scales for uncertainty judgement. One example is Barnes, (2016), in which the author provided the probability mapping standards used in the Canadian 
Security Intelligence Service. This scale vertically displays numerical probabilities expressed as frequencies. Inspired by these studies, we propose a strategy to use uncertainty expressions for objective uncertain information and refer it to the Verbal-Numerical Scale (V-N Scale).

\section{V-N Disclosure: Subjective accounting information}

V-N Disclosure represents the approach of disclosing subjective accounting information with an additional disclosure of the subjective uncertainty expressions, followed by a mathematical calculation. V-N Disclosure thus uses mathematics to help both providers and users communicate uncertain accounting information transparently. The V-N Disclosure approach requires one of the two types of additional information in the financial report:

Additional information 1: The absolute value of the uncertain accounting item when the chances of economic benefits flow relate to this item is absolutely certain - in other words, $100 \%$ chance, or

Additional information 2: A subjective numerical interpretation made by management in association with the use of verbal uncertainty expressions for this uncertain accounting item.

To a certain extent, all uncertainties can be described with a maximum certainty interval in numbers or words. For example, the occurrence of each uncertain event must drop within the $[0,1]$ probability range. Alternatively, it can be described as being between absolutely no chance $(0 \%$ chance) or absolutely certain $(100 \%$ chance). This shows that the maximum uncertainty interval is universally applicable for all uncertainty descriptions.

Knowing the maximum certainty interval $[0,1]$ may not prove meaningful for decisionmaking. To make it meaningful, users of uncertain information need to narrow it down to a 'comfortable uncertainty level',

In the context of accounting, a comfortable uncertainty level means that uncertain accounting information will be communicated or interpreted without personal biases and will not result in a material misstatement. However, providing uncertain accounting information with a comfortable uncertainty level is challenging: there are both. subjective and objective uncertainties in accounting, and estimating the uncertainties in the absence of verbal probability expression scales may be difficult or impossible. For example, many reporting entities state that the accounting estimate is based on managers' best estimation, but provide no verbal probability expressions scales to quantify their estimation. The following example illustrates how the V-N Disclosure approach can address this issue.

An accounting-information user wants to assess the value of inventories that are expressly subject to management's estimation ${ }^{7}$.

a) In the annual report, the reporting entity discloses that these inventories are worth $\$ 10$ million.

b) This is based on the management's best estimate on the 'probable' future economic benefits inflow (Additional information 2).

\footnotetext{
${ }^{6}$ The authors define the comfortable uncertainty level as the narrowest range of estimation; if possible, as narrow as the point estimate number, such as ' $37 \% \pm 0 \%$ '.

${ }^{7}$ Notably, this example excludes the inventories where the valuation is not subject to uncertainty. It only counts the portion where the inventories' realisable values are uncertain, and the valuation process is subject to management's estimation.
} 
c) If all of these inventories are worthless, then the total value is $\$ 0$.

d) If all of the future economic benefit inflow of the inventory is absolutely certain, then the total value of this inventory is the value \$A (Additional information 1).

The mathematical strategy is based on these rules:

1. All uncertain events have a universal maximum probability range interval: $[0,1]$.

2. Knowing the two additional pieces of information would allow accountinginformation users to calculate and understand the real state of the business.

The value range of inventories can be described as:

$\$ 0$ to $\$ A(0<\mathrm{p}<1)$

$\$ 0$ to $\$ 10$ million $(0<\mathrm{p}<$ 'probable')

If the company can assert that $\$ A=\$ 15$ million, the numerical meaning of 'probable' can be determined:

$$
\text { Probable }=67 \%(\$ 10 \text { million } \div \$ 15 \text { million })
$$

If the company can assert that their interpretation of probable $=80 \%$, the dollar value of $\$ \mathrm{~A}$ can be determined:

$\$ A=\$ 12.5$ million $(\$ 10$ million $\div 80 \%)$

\section{Discussion of V-N Scale and V-N Disclosure}

When uncertain information involves objective properties, the preciseness of the uncertainty information is determined by the quality and availability of both new information and existing knowledge. In this case, a plausible approach would be to choose the least vague verbal expressions to describe the uncertainty information; this should yield the smallest variations in numerical interpretation. As discussed earlier, accounting information contains a significant number of uncertainty expressions. This is particularly concerning when the regulators of accounting standards also use uncertainty expressions in pronouncements.

The V-N Scale provides a valid solution to the need to enhance the reliability of uncertain accounting information. The V-N Scale enables information users to make judgements based on an understanding of the level of uncertainty (e.g., the error range). The disclosure of such information also allows information preparers to continually monitor the level of uncertainty, thereby promoting the accuracy of the financial report.

Similarly, when uncertain information is subjective, the preciseness of the uncertainty information is often determined by the best judgement of the information preparers. As discussed earlier, the V-N Disclosure approach requires information about either the absolute dollar value when the uncertain event is deemed to have occurred; or the subjective numerical interpretation associated with the use of verbal uncertainty expressions.

The V-N Disclosure provides three useful benefits for accounting-information preparers and users. First, it provides a certainty range, allowing analysis and estimation to be more rational. For example, XYZ Company has total assets worth between $\$ 100$ million and $\$ 150$ million, subject to the interpretation of the company's judgement. Knowing this certainty range allows accounting-information users to better understand the financial position, although the exact value of assets is unknown. 
Second, the V-N Disclosure effectively reduces biases in the disclosure of uncertain accounting information. This is because the first item of additional information reflects the true state of business value, and the second represents the true beliefs of the providers of uncertain information. Thus, the reporting entity would find V-N Disclosure to be an easy strategy for providing transparent information, even when the information is subjectively uncertain.

Third, the V-N Disclosure allows information users to evaluate the information providers' judgement. For example:

- If the company's interpretation of 'likely' is $85 \%$, this results in a specific number on its financial statement.

- Investors or analysts can exercise their judgement on 'likely' and arrive at dollar figures for the financial statements.

Admittedly, V-N Scale and V-N Disclosure both have limitations. For example, V-N Scale must be standardised in a way that makes it comparable across different languages. Such a challenge must address not only translation issues (Evans, 2004, 2010; Evans, Baskerville, \& Nara, 2015) but also the constraints inherent in linguistic relativism. As the linguistic relativism theory described, individuals' spoken language determines and shapes their world view (Gumperz \& Levinson, 1991; Kay \& Kempton, 1984). Similarly, applying the V-N Disclosure in financial reporting can be less motivating than using verbal expressions alone. As discussed earlier, people who prepare uncertainty information prefer to use verbal uncertainty expressions because they allow a certain degree of flexibility and subjectivity. Furthermore, acknowledging the inherent linguistic variances between languages would also mean a perfectly comparable V-N Scale or V-N Disclosure is almost impossible. Nevertheless, both strategies aim to help achieve the purpose of financial reporting, which is to provide accounting information useful to existing and potential users in 'making decisions about providing resources to the entity' (Conceptual Framework, OB 2).

\section{Conclusion}

Using uncertainty expressions to communicate uncertain information is a common practice in accounting. A thorough review of the latest IFRS and IAS reports suggests that even standard-setters cannot avoid using uncertainty expressions in their pronouncements. Our latest research reveals that the IFRS and IAS use about 40 different uncertainty expressions covering almost every aspect of financial reporting.

Although using uncertainty expressions for financial reporting is a common practice in accounting, it also causes concerns about information quality and communication efficiency. Prior studies have stressed that use uncertainty expressions in financial reporting could cause inconsistent interpretations; thus, lowing the information quality and communication efficiency. The current paper provides a systematic discussion of uncertainty expressions in accounting. First, it distinguishes different modes of uncertainty expressions and reviews examples of how uncertainty expressions are used in accounting standards. Then, it provides an overview of relevant literature and defines the three main research paradigms for uncertainty expressions. It also outlines some empirical findings regarding communication biases when using uncertainty expressions and discussed how they affect uncertainty judgement. This discussion highlights the fundamental concerns of using uncertainty expressions in accounting and the need for a solution for users and preparers of accounting information. 
In responding to these practical concerns, this paper has sought to clarify the different contexts of uncertainty in accounting. Based on the characteristics of each context, it has proposed two solutions: V-N Scale and V-N Disclosure, both of which are drawn from relevant theories and practical implementations from the behaviour-psychology literature.

The V-N Scale targets objective uncertainties and appears to be a widely acceptable solution in different domains, such as metrology, intelligent analysis, and psychology. The V-N Disclosure targets subjective uncertainties, allowing information preparers to freely use verbal uncertainty expressions without fear of losing information accuracy. This strategy should also benefit investors who themselves prefer self-assessment of the uncertainty information for decision-making.

Although it is still impractical to design a one-size-fits-all standard for the use of uncertainty expressions in accounting, our proposed strategies complement the traditional word-tonumber methods. For example, by distinguishing the objective and subjective nature of uncertainty information, our strategies can reduce the ambiguity of meaning and improve the accuracy of information.

Future studies can focus on solving two further issues related to uncertainty expressions in accounting. First, existing modes of uncertainty expressions are still limited to either verbal or numerical uncertainty expressions. Innovation in reporting uncertain information is rare and would require accounting scholars to break the fundamental barriers to the modes of uncertainty expressions. A potential avenue for such breakthrough is by using information technology to combine theories of linguistics, psychology, and cognition to devise new methods of reporting uncertainties.

Second, research methods on uncertainty expressions are still primarily based on surveys or laboratory experiments. The development of databases used in accounting research, and particularly the increasing availability of 'big data', offer a promising research opportunity to use naturally occurring datasets (Paxton \& Griffiths, 2017; Teoh, 2018), such as Google Trends, to trace people's perceptions of different uncertainty expressions over time. Also, ideally, this could offer a way to map uncertainty-expression scales across different culture and language contexts. 


\section{References}

ABC News. (2016), "Australian credit rating: 'Reasonably high' chance AAA will be lost preChristmas", available at: http://www.abc.net.au/news/2016-12-13/australia-likely-to-lose-aaarating-next-week/8117224 (accessed 13 December 2016).

ABC News. (2017a), "Recession unlikely, interest rates set to remain steady: RBA Statement on Monetary Policy", available at: http://www.abc.net.au/news/2017-02-10/rba-quarterlystatement $/ 8258470$ (accessed 10 February 2017).

ABC News. (2017b), "Sydney terror raids 'disrupted' plot to bring down plane", available at: http://www.abc.net.au/news/2017-07-30/plot-to-bring-down-plane-disrupted,-pm-says-aftersydney-raids/8757386 (accessed 30 July 2017).

Amer, T., Hackenbrack, K. and Nelson, M. (1994), "Between-auditor differences in the interpretation of probability phrases", Auditing: A Journal of Practice \& Theory, Vol. 13 No. 1, pp. 126136.

Australian National Security. (2017), "National terrorism threat advisory system", available at: https://www.nationalsecurity.gov.au/securityandyourcommunity/pages/national-terrorismthreat-advisory-system.aspx (accessed 30 July 2017).

Barnes, A. (2016), "Making intelligence analysis more intelligent: Using numeric probabilities", Intelligence and National Security, Vol. 31 No. 3, pp. 327-344.

Beyth-Marom, R. (1982), "How probable is probable? A numerical translation of verbal probability expressions", Journal of Forecasting, Vol. 1 No. 3, pp. 257-269.

Bloomfield, R. J. (2008), "Accounting as the language of business", Accounting Horizons, Vol. 22 No. 4, pp. 433-436.

Bonnefon, J.-F. and Villejoubert, G. (2006), "Tactful or Doubtful?:Expectations of Politeness Explain the Severity Bias in the Interpretation of Probability Phrases", Psychological Science, Vol. 17 No. 9, pp. 747-751.

Bradbury, M. E. and Schröder, L. B. (2012), "The content of accounting standards: Principles versus rules", The British Accounting Review, Vol. 44 No. 1, pp. 1-10.

Brun, W. and Teigen, K. H. (1988), "Verbal probabilities: Ambiguous, context-dependent, or both?", Organizational Behavior and Human Decision Processes, Vol. 41 No. 3, pp. 390-404.

Budescu, D. V., Broomell, S. and Por, H.-H. (2009), "Improving communication of uncertainty in the reports of the Intergovernmental Panel on Climate Change", Psychological Science, Vol. 20 No. 3, pp. 299-308.

Budescu, D. V., Karelitz, T. M. and Wallsten, T. S. (2003), "Predicting the directionality of probability words from their membership functions", Journal of Behavioral Decision Making, Vol. 16 No. 3, pp. 159-180.

Budescu, D. V., Por, H. and Broomell, S. B. (2012), "Effective communication of uncertainty in the IPCC reports: A nationally representative survey", Climatic Change, Vol. 113, pp. 181-200.

Budescu, D. V., Weinberg, S. and Wallsten, T. S. (1988), "Decisions based on numerically and verbally expressed uncertainties", Journal of Experimental Psychology: Human Perception and Performance, Vol. 14 No. 2, pp. 281-294.

Chand, P., Cummings, L. and Patel, C. (2012), "The effect of accounting education and national culture on accounting judgments: A comparative study of Anglo-Celtic and Chinese culture", European Accounting Review, Vol. 21 No. 1, pp. 153-182.

Chesley, G. R. (1986), "Interpretation of uncertainty expressions", Contemporary Accounting Research, Vol. 2 No. 2, pp. 179-199.

Conceptual Framework. "The Conceptual Framework for Financial Reporting", in Recognition of the elements of financial statements. IFRS Foundation.

Davidson, R. A. (1991), "Practical Difficulties Encountered in Selecting Uncertainty Words: The Example of Accounting Standards", Applied Psychology, Vol. 40 No. 4, pp. 353-363.

Davidson, R. A. and Chrisman, H. H. (1994), "Translations of uncertainty expressions in Canadian accounting and auditing standards", Journal of International Accounting, Auditing and Taxation, Vol. 3 No. 2, pp. 187-203.

Deloitte. (2017), "Accounting Infrastructure: A Booster to the Belt and Road Initiative", in. 
Doupnik, T. S. and Riccio, E. L. (2006), "The influence of conservatism and secrecy on the interpretation of verbal probability expressions in the Anglo and Latin cultural areas", The International Journal of Accounting, Vol. 41 No. 3, pp. 237-261.

Doupnik, T. S. and Richter, M. (2003), "Interpretation of uncertainty expressions: a cross-national study", Accounting, Organizations and Society, Vol. 28 No. 1, pp. 15-35.

Doupnik, T. S. and Richter, M. (2004), "The impact of culture on the interpretation of "In Context" verbal probability expressions", Journal of International Accounting Research, Vol. 3 No. 1, pp. $1-20$.

$\mathrm{Du}, \mathrm{N}$. and Stevens, K. (2011), "Numeric-to-verbal translation of probability expressions in SFAS 5", Managerial Auditing Journal, Vol. 26 No. 3, pp. 248-262.

Ellsberg, D. (1961), "Risk, ambiguity, and the savage axioms", The Quarterly Journal of Economics, Vol. 75 No. 4, pp. 643-669.

Erb, C. and Pelger, C. (2015), "“Twisting words"? A study of the construction and reconstruction of reliability in financial reporting standard-setting", Accounting, Organizations and Society, Vol. 40, pp. 13-40.

Erev, I. and Cohen, B. L. (1990), "Verbal versus numerical probabilities: Efficiency, biases, and the preference paradox", Organizational Behavior and Human Decision Processes, Vol. 45 No. 1, pp. 1-18.

Evans, L. (2004), "Language, translation and the problem of international accounting communication", Accounting, Auditing \& Accountability Journal, Vol. 17 No. 2, pp. 210-248.

Evans, L. (2010), "Observations on the changing language of accounting", Accounting History, Vol. 15 No. 4, pp. 439-462.

Evans, L., Baskerville, R. and Nara, K. (2015), "Colliding worlds: Issues relating to language translation in accounting and some lessons from other disciplines", Abacus, Vol. 51 No. 1, pp. $1-36$.

Gonzalez-Vallejo, C. C., Erev, I. and Wallsten, T. S. (1994), "Do decision quality and preference order depend on whether probabilities are verbal or numerical?", The American Journal of Psychology, pp. 157-172.

Gumperz, J. J. and Levinson, S. C. (1991), "Rethinking linguistic relativity", Current Anthropology, Vol. 32 No. 5, pp. 613-623.

Hamm, R. M. (1991), "Selection of verbal probabilities: A solution for some problems of verbal probability expression", Organizational Behavior and Human Decision Processes, Vol. 48 No. 2, pp. 193-223.

Hardman, D. and Macchi, L. (2003), Thinking: Psychological Perspectives on Reasoning, Judgment, and Decision Making, John Wiley \& Sons, England.

Harris, A. J. L. and Corner, A. (2011), "Communicating environmental risks: Clarifying the severity effect in interpretations of verbal probability expressions", Journal of Experimental Psychology: Learning, Memory, and Cognition, Vol. 37 No. 6, pp. 1571-1578.

Hu, C., Chand, P. and Evans, E. (2013), "The Effect of national culture, acculturation, and education on accounting judgments: a comparative study of Australian and Chinese culture", Journal of International Accounting Research, Vol. 12 No. 2, pp. 51-77.

Huerta, E., Petrides, Y. and Braun, G. P. (2013), "Translation of IFRS: Language as a barrier to comparability", Research in Accounting Regulation, Vol. 25 No. 1, pp. 1-12.

Huerta, E., Petrides, Y. and Braun, G. P. (2016), "Interpretation of probability expressions in accounting: The effects of frame switching", Journal of International Accounting, Auditing and Taxation, Vol. 27, pp. 1-12.

IFRS 5 . Appendix A. (2016), "IFRS 5 Non-current Assets Held for Sale and Discontinued Operations", in. IFRS Foundation, London.

IFRS 13 (2016), "IFRS 13 Fair Value Measurement", in. IFRS Foundation, London.

IFRS Foundation. (2016), "The global financial reporting language", in, UK.

IFRS Foundation. (2019), "Who uses IFRS Standards?", available at: http://www.ifrs.org/use-aroundthe-world/use-of-ifrs-standards-by-jurisdiction/\#analysis (accessed 01 May 2019).

Jaffe-Katz, A., Budescu, D. V. and Wallsten, T. S. (1989), "Timed magnitude comparisons of numerical and nonnumerical expressions of uncertainty", Memory \& Cognition, Vol. 17 No. 3, pp. 249-264. 
Johnson, E. M. (1973), "Numerical encoding of qualitative expressions of uncertainty", in. Army research instituition for the behavioral and social sciences, pp. 1-17.

Joint Committee for Guides in Metrology. (2010), "Evaluation of measurement data - Guide to the expression of uncertainty in measurement", in. Bureau International des Poids et Mesures.

Juanchich, M. and Sirota, M. (2013), "Do people really say it is "likely" when they believe it is only "possible"? Effect of politeness on risk communication", The Quarterly Journal of Experimental Psychology, Vol. 66 No. 7, pp. 1268-1275.

Juanchich, M., Sirota, M. and Butler, C. L. (2012), "The perceived functions of linguistic risk quantifiers and their effect on risk, negativity perception and decision making", Organizational Behavior and Human Decision Processes, Vol. 118 No. 1, pp. 72-81.

Karelitz, T. M. and Budescu, D. V. (2004), "You say "Probable" and I say "Likely": Improving interpersonal communication with verbal probability phrases", Journal of Experimental Psychology: Applied, Vol. 10 No. 1, pp. 25-41.

Kay, P. and Kempton, W. (1984), "What Is the Sapir-Whorf Hypothesis?", American Anthropologist, Vol. 86 No. 1, pp. 65-79.

Kelton, A. S. and Montague, N. R. (2018), "The unintended consequences of uncertainty disclosures made by auditors and managers on nonprofessional investor judgments", Accounting, Organizations and Society, Vol. 65, pp. 44-55.

Laswad, F. and Mak, Y. T. (1997), "Interpretations of probability expressions by New Zealand standard setters", Accounting Horizons, Vol. 11 No. 4, pp. 16-23.

Laswad, F. and Mak, Y. T. (1999), "Interpretations of probability expressions: A comparison between standard-setters and accountants", Pacific Accounting Review, Vol. 11 No. 2, pp. 241-254.

Lichtenstein, S. and Newman, J. R. (1967), "Empirical scaling of common verbal phrases associated with numerical probabilities", Psychonomic Science, Vol. 9 No. 10, pp. 563-564.

Mosteller, F. and Youtz, C. (1990), "Quantifying probabilistic expressions", Statistical Science, Vol. 5 No. 1, pp. 2-12.

Nelson, M. W. and Kinney Jr, W. R. (1997), "The effect of ambiguity on loss contingency reporting judgments", The Accounting Review, pp. 257-274.

Oxford English Dictionary. (2002), "'ambiguity"", in Oxford English Dictionary. Oxford University Press.

Paxton, A. and Griffiths, T. L. (2017), "Finding the traces of behavioral and cognitive processes in big data and naturally occurring datasets", Behavior Research Methods, Vol. 49 No. 5, pp. 16301638.

Piercey, M. D. (2009), "Motivated reasoning and verbal vs. numerical probability assessment: Evidence from an accounting context", Organizational Behavior and Human Decision Processes, Vol. 108 No. 2, pp. 330-341.

Reagan, R. T., Mosteller, F. and Youtz, C. (1989), "Quantitative meanings of verbal probability expressions", Journal of Applied Psychology, Vol. 74 No. 3, pp. 433-442.

Reimers, J. L. (1992), "Additional evidence on the need for disclosure reform", Accounting Horizons, Vol. 6 No. 1, pp. 36-41.

Risbey, J. S. and Kandlikar, M. (2007), "Expressions of likelihood and confidence in the IPCC uncertainty assessment process", Climatic Change, Vol. 85 No. 1, pp. 19-31.

Salleh, S. I. M., Gardner, J. C., Sulong, Z. and McGowan, C. B. (2011), "The interpretation of" in context" verbal probability expressions used in International Accounting Standards: a comparison of English and Chinese students studying at English speaking universities", Journal of International Education Research, Vol. 7 No. 2, pp. 67-80.

Segal, U. (1987), "The ellsberg paradox and risk aversion: An anticipated utility approach", International Economic Review, Vol. 28 No. 1, pp. 175-202.

Simon, J. (2002), "Interpretation of probability expressions by financial directors and auditors of UK companies", European Accounting Review, Vol. 11 No. 3, pp. 601-629.

Teigen, K. H. and Brun, W. (1999), "The directionality of verbal probability expressions: Effects on decisions, predictions, and probabilistic reasoning", Organizational Behavior and Human Decision Processes, Vol. 80 No. 2, pp. 155-190.

Teigen, K. H. and Brun, W. (2003), "Verbal probabilities: a question of frame?", Journal of Behavioral Decision Making, Vol. 16 No. 1, pp. 53-72. 
Teoh, S. H. (2018), "The promise and challenges of new datasets for accounting research", Accounting, Organizations and Society, Vol. 68-69, pp. 109-117.

Wallsten, T. S., Budescu, D. V., Zwick, R. and Kemp, S. M. (1993), "Preferences and reasons for communicating probabilistic information in verbal or numerical terms", Bulletin of the Psychonomic Society, Vol. 31 No. 2, pp. 135-138.

Wallsten, T. S., Fillenbaum, S. and Cox, J. A. (1986), "Base rate effects on the interpretations of probability and frequency expressions", Journal of Memory and Language, Vol. 25 No. 5, pp. 571-587.

Weiss, C. (2008), "Communicating Uncertainty in Intelligence and Other Professions", International Journal of Intelligence and CounterIntelligence, Vol. 21 No. 1, pp. 57-85.

Windschitl, P. D. and Wells, G. L. (1996), "Measuring psychological uncertainty: Verbal versus numeric methods", Journal of Experimental Psychology: Applied, Vol. 2 No. 4, pp. 343-364.

Witteman, C. and Renooij, S. (2003), "Evaluation of a verbal-numerical probability scale", International Journal of Approximate Reasoning, Vol. 33 No. 2, pp. 117-131.

$\mathrm{Xu}$, J.-H., Ye, X.-B. and Li, S. (2009), "Communication mode preference paradox among native chinese speakers", The Journal of Social Psychology, Vol. 149 No. 1, pp. 125-130.

Zeff, S. A. (2007), "Some obstacles to global financial reporting comparability and convergence at a high level of quality", The British Accounting Review, Vol. 39 No. 4, pp. 290-302. 


\section{Appendix 1}

\section{List of uncertainty expressions and examples of their usage}

\begin{tabular}{|c|c|c|}
\hline \multirow[b]{2}{*}{ Uncertainty expressions } & \multicolumn{2}{|c|}{ Examples of usage } \\
\hline & $\begin{array}{c}\text { International Accounting Standards } \\
\text { (IAS) }\end{array}$ & $\begin{array}{c}\text { International Financial Reporting } \\
\text { Standards (IFRS) }\end{array}$ \\
\hline certainty & $1,7,11,38$ & Framework, 6,13 \\
\hline deemed & $16,17,19,29,33,37,40$ & $1,3,9,10,13$ \\
\hline expected & $1,2,8,12$ & Framework, 2, 3 \\
\hline highly likely & 40,41 & \\
\hline highly probable & 39 & $5,9,15$ \\
\hline highly unlikely & 40 & 4,9 \\
\hline improbable & & Framework \\
\hline insignificant & $7,16,32,40$ & $4,7,9$ \\
\hline less likely & & 3,10 \\
\hline likely & $1,11,19,2,28,36,37,38,39$ & Framework, $1,2,3,4,9,10,13,15,16$ \\
\hline more likely than not & 37 & 5 \\
\hline most likely & 36,37 & $2,13,15$ \\
\hline no longer probable & 12,37 & \\
\hline not expected & $1,11,19,32,36,39$ & $3,9,14,15$ \\
\hline not possible & $26,28,36$ & Framework, 2, 9 \\
\hline not probable & 12,37 & 3 \\
\hline possible & $\begin{array}{l}1,8,11,17,20,21,24,28,32,34,36 \text {, } \\
37,38,39,40,41\end{array}$ & Framework, 2, 3, 4, 7, 9, 10, 13, 15 \\
\hline probable & $12,16,23,28,37,38,40,41$ & Framework, $3,9,15$ \\
\hline reasonable assurance & 20 & \\
\hline reasonably possible & $1,11,19$ & $4,7,9,13,15$ \\
\hline reliably & $12,16,17,23,28,34,38,39,40,41$ & Framework, $2,3,4,7,9,15,16$ \\
\hline remote & $16,17,36,37,41$ & $7,9,12,15$ \\
\hline significant & $1,7,16,36$ & $1,4,7,9,13$ \\
\hline substantially & $1,11,12,17,21,23,32,38$ & $2,3,8,9,10,11,13,15,16$ \\
\hline sufficiently & $1,11,17,19,37$ & Framework, $4,5,9,10,16$ \\
\hline sufficiently lower & 17 & 16 \\
\hline uncertain & $1,11,17,19,32,36,37$ & $3,4,7,13,15$ \\
\hline unlikely & $12,17,19,26,32,36,37,38$ & Framework, $4,5,6,9,10$ \\
\hline very unlikely & 32 & 9 \\
\hline virtually certain & $19,32,37,38$ & \\
\hline
\end{tabular}




\section{Appendix 2}

\begin{tabular}{|c|c|c|c|c|c|c|}
\hline Expressions & $\begin{array}{l}\text { Mean } \\
\text { Value }\end{array}$ & $\begin{array}{l}\text { Std. } \\
\text { Dev. }\end{array}$ & Literature & Participants & Language & Location \\
\hline Possible & $33.47 \%$ & $16.15 \%$ & $\begin{array}{l}\text { Laswad and Mak, } \\
\text { (1999) }\end{array}$ & Standard-setters & English & $\begin{array}{l}\text { New } \\
\text { Zealand }\end{array}$ \\
\hline \multirow[t]{16}{*}{$\begin{array}{l}45.19 \% \\
\text { (Average) }\end{array}$} & $48.87 \%$ & $11.85 \%$ & $\begin{array}{l}\text { Laswad and Mak, } \\
\text { (1999) }\end{array}$ & Accountants & English & $\begin{array}{l}\text { New } \\
\text { Zealand }\end{array}$ \\
\hline & $49.59 \%$ & $13.80 \%$ & $\begin{array}{l}\text { Amer, Hackenbrack, } \\
\text { and Nelson, (1994) }\end{array}$ & Auditor & English & USA \\
\hline & $52.00 \%$ & & Reimers, (1992) & Auditor & English & USA \\
\hline & $48.90 \%$ & & Reimers, (1992) & $\begin{array}{l}\text { Engineering } \\
\text { managers }\end{array}$ & English & USA \\
\hline & $49.90 \%$ & & Reimers, (1992) & Marketing managers & English & USA \\
\hline & $52.60 \%$ & & Reimers, (1992) & MBA students & English & USA \\
\hline & $37.00 \%$ & $23.00 \%$ & $\begin{array}{l}\text { Lichtenstein and } \\
\text { Newman, (1967) }\end{array}$ & $\begin{array}{l}\text { Company } \\
\text { employees }\end{array}$ & English & USA \\
\hline & $50.60 \%$ & $16.90 \%$ & Johnson, (1973) & $\begin{array}{l}\text { Army and college } \\
\text { students }\end{array}$ & English & USA \\
\hline & $38.00 \%$ & $12.00 \%$ & $\begin{array}{l}\text { Brun and Teigen, } \\
\text { (1988) }\end{array}$ & Psychology students & Norwegian & Norway \\
\hline & $42.67 \%$ & $13.43 \%$ & Budescu et al., (1988) & Psychology students & English & Israel \\
\hline & $42.12 \%$ & $11.50 \%$ & Budescu et al., (1988) & Psychology students & English & Israel \\
\hline & $40.00 \%$ & & Reagan et al., (1989) & Psychology students & English & USA \\
\hline & $41.00 \%$ & & Simon, (2002) & Financial Director & English & UK \\
\hline & $42.00 \%$ & & Simon, (2002) & Auditors & English & UK \\
\hline & $50.66 \%$ & $13.19 \%$ & Davidson, (1991) & Accountants & English & USA \\
\hline & $48.85 \%$ & $18.27 \%$ & Davidson, (1991) & Accounting students & English & USA \\
\hline Uncertain & $40.00 \%$ & $14.00 \%$ & $\begin{array}{l}\text { Lichtenstein and } \\
\text { Newman, (1967) }\end{array}$ & $\begin{array}{l}\text { Company } \\
\text { employees }\end{array}$ & English & USA \\
\hline \multirow[t]{2}{*}{$\begin{array}{l}41.47 \% \\
\text { (Average) }\end{array}$} & $44.00 \%$ & $15.00 \%$ & $\begin{array}{l}\text { Brun and Teigen, } \\
\text { (1988) }\end{array}$ & Psychology students & Norwegian & Norway \\
\hline & $40.40 \%$ & $12.20 \%$ & Hamm, (1991) & Psychology students & English & USA \\
\hline
\end{tabular}

